\title{
AS CARACTERÍSTICAS DO MERCADO DE HORTIFRUTIGRANJEIROS EM LONDRINA *
}

\author{
ROSSANA LOTT RODRIGUES ${ }^{1}$ \\ ANTONIO CARLOS MORETTO' \\ CARLOS ROBERTO FERREIRA ${ }^{1}$
}

RODRIGUES, R.L.; MORETTO, A.C.; FERREIRA, C.R. As características do mercado de hortifrutigranjeiros
em Londrina. Semina: Londrina, Ci. Sociais/Humanas, v. 17. n. 3, p. 345-349, set. 1996.

RESUMO: O objetivo desse texto é divulgar as primeiras informações sobre as características dos agentes que compõem o mercado de hortifrutigranjeiros em Londrina. Foram estudados 28 produtos identificados como os mais comercializdos e consumidos no município. Os dados foram coletados através de formulários aplicados junto a produtores, atacadistas, varejistas e consumidores. Como principais considerações finais destacam-se a passividade dos produtores na formação dos preços, a pequena dependência total de Londrina em relação ao fornecimento externo, a importância do Mercadão como ponto de ligação entre produtores e varejistas e a supremacia dos supermercados na comercialização de hortifrutigranjeiros.

PALAVRAS-CHAVE: hortifrutigranjeiros - comercialização - mercado

\section{1 - INTRODUÇÃo}

A comercialização agrícola e o abastecimento alimentar no Brasil passam a desempenhar um papel cada vez mais importante à medida que ocorre o crescimento e o desenvolvimento econômico. Questões relacionadas à influência da comercialização na renda dos agentes envolvidos no processo, principalmente os produtores, ao problema da classificação, padronização e qualidade dos alimentos colocados à disposição dos consumidores nos centros urbanos e à influência que o caminho percorrido do produtor ao consumidor final exerce nos preços dos produtos agrícolas, dentre outras, são pontos que vêem merecendo estudos constantes.

A nível regional e considerando os mercados de produtos hortifrutigranjeiros, embora existam características semelhantes em cada cidade, especificidades regionais no que se refere a produção local, dependência externa, grau de organização dos agentes, renda dos consumidores, proximidade de grandes centros abastecedores, dentre outras, definem as particularidades do processo de comercialização e da organização destes mercados em cada localidade.

Dentro desse contexto, um estudo incluindo um maior número de produtos e buscando um maior conhecimento da estrutura do mercado de hortifrutigranjeiros em Londrina se reveste de interesse maior, notadamente quando se considera o fato de que as condições potenciais da região permitem a implantação de programas agrícolas visando a elevar os rendi- mentos das hortaliças, frutas e ovos, a renda recebida, principalmente, pelos produtores e, conseqüentemente, a melhorar o bem-estar social.

Assim, o objetivo maior desse texto é divulgar os primeiros resultados de uma pesquisa sobre a estrutura de mercado e a formação de preços dos hortifrutigranjeiros em Londrina. Especificamente, pretende-se caracterizar os agentes da cadeia de comercialização daqueles produtos, quais sejam, os produtores, atacadistas e varejistas. Os consumidores, por serem o fim de todo o processo, serão, também, incluídos nesta caracterização.

\section{2 - MATERIAL E MÉTODO}

Os dados para esta divulgação foram levantados durante o período de um ano, de julho/94 a junho/95, no município de Londrina e incluíram 28 produtos identificados pelos técnicos da EMATER, local como os mais comercializados e consumidos no mercado londrinense, a saber: abobrinha, alface, batata doce, batata inglesa, beterraba, cebola, cenoura, chuchu, couve-flor, feijão vagem, mandioca, pepino, pimentão, repolho, tomate, abacate, abacaxi, banana, caqui, laranja, maçã, mamão, maracujá, melancia, morango, poncã, uva e ovos.

As informações foram obtidas através de formulários aplicados a produtores, atacadistas, varejistas e consumidores. Foram entrevistados 151 produtores, divididos nas categorias proprietário, porcenteiro, meeiro

\footnotetext{
Professores do Departamento de Economia/Universidade Estadual de Londrina, Caixa Postal 6001, Londrina, PR, CEP 86051-990

* Esta divulgação é parte de uma pesquisa desenvolvida pelos autores. Agradecemos à Prof ${ }^{2}$ Solange de Cássio Inforzato de Souza, aos técnicos da Secretaria de Agricultura e Abastecimento da Prefeitura de Londrina Osvaldo de Souza Campos Junior e Paulo Gonçalves da Silva e aos estagiários do Curso de Ciências Econômicas Alessandra Bastiani dos Santos, Clovis Junior Caldeirão, Darlene Cristina Ribeiro, Izabel Cristina do Nascimento, Regina Lúcia Sanches Malassise e Tarciso José Cerantola Filho pelas valiosas contribuições e pelos trabalhos desenvolvidos durante a coleta das informações.
} 
e arrendatário, 60 atacadistas (que correspondem ao universo de atacadistas no Mercadāo e na CEASA), sendo $14 \mathrm{com}$ box na CEASA, 42 no Mercadão e $4 \mathrm{em}$ ambos, 73 varejistas dentre supermercados, feiras-livres, sacolōes e Mercado Municipal, e 1009 consumidores, distribuidos em 6 classes de renda (até 2 salários mínimos - SM, de 2 a 4 SM, de 4 a 6 SM, de 6 a 8 $\mathrm{SM}$, de 8 a $10 \mathrm{SM}$ e mais de $10 \mathrm{SM}$ ) escolhidos aleatoriamente entre os equipamentos varejistas da cidade.

As informaçōes adquiridas visaram subsidiar as análises relativas à caracterização e organização dos agentes que compöem a cadeia de comercialização de hortifrutigranjeiros em Londrina, além de permitir detec- tar o relacionamento, a integração e diversificação de suas atividades, o grau de concentração, as formas de concorrência, o poder de cada um na determinação dos preços pagos e recebidos, a preocupação com a qualidade, a classificação e padronização dos produtos, o grau de satisfação e as sugestōes para melhorar o processo de comercialização.

Os consumidores, embora não façam parte da cadeia de comercializaçăo em foco, foram incluidos no estudo por ser o alvo final de todo o processo. Neste sentido, os dados levantados permitiram informaçōes relativas às suas características, como freqüência de consumo, locais de copra e determinação da escolha dos produtos e de onde comprar.

\section{3 - RESULTADOS}

\section{1 - Caracterização dos produtores}

Dos 151 produtores entrevistados, $70,2 \%$ são proprietários, $23,2 \%$ arrendatários, $4,6 \%$ meeiros e 2,0\% porcenteiros. Em termos de área, independente da categoria, 58,9\% trabalham em estabelecimentos de até $10 \mathrm{ha}, 35,1 \%$ em área de 10 a $50 \mathrm{ha}, 4,0 \%$ em área de 50 a 100 ha e $2,0 \%$ em áreas maiores do que 100 ha.

As informações mostraram que 24 dos 28 produtos estudados são cultivados pelos produtores do município, revelando a dependência total do mercado londrinense apenas com relação a batata inglesa, abacaxi, mamão e melancia. Além do cultivo dos produtos alvo da pesquisa, $67,5 \%$ dos produtores afirmaram plantar outros produtos, sendo a categoria proprietário a que mais desenvolve outras atividades, seguida dos arrendatários, meeiros e porcenteiros.

A classe dos produtores é pouco organizada no município, com apenas $27,2 \%$ deles fazendo parte de alguma associação ou organização. Por outro lado, 49\% recebem orientação técnica. Em ambos os casos, a categoria proprietário se destaca em termos do número de produtores.

No que se refere aos locais de venda dos produtos hortifrutigranjeiros, tem-se que o Mercadão é o mais significativo, com $65,6 \%$ dos entrevistados comercializando seus produtos somente neste ponto, seguido de $6 \%$ dos produtores vendendo no Meradão e na CEASA e 5,3\% no Mercadão e em outros locais.

Os produtores, ao venderem seus produtos, precisam atender a algumas exigências dos compradores. Dentre estas a mais importante é a classificação dos produtos apontada por $81,5 \%$ dos entrevistados, seguida pelo prazo de pagamento citado por $45,7 \%$ dos produtores. Diante disto, $98 \%$ dos produtores afirmaram praticar algum tipo de classificação e padronização dos seus produtos, que pode ser por tamanho, cor, qualidade e grau de maturação. As razões para a classificação são a obtenção de melhores preços, a manutenção do mercado, a agilização das vendas e as vendas dos produtos a preços diferenciados. Além disso, todos os compradores são exigentes para os produtores.

No que se refere à qualidade dos produtos, a preocupação existe para $98,7 \%$ dos produtores, um percentual praticamente igual ao de produtores que praticam a classificação. De certa forma, a classificação dos produtos está associada à qualidade, sendo as razões as mesmas para ambas.

Na comercialização dos produtos, a determinação do preço de venda é feita pelo merado, ou seja, vigora a lei da oferta e da procura, e o pagamento é feito a vista e a prazo em $89,4 \%$ dos casos. Dentro desse processo, $58,9 \%$ dos produtores está insatisfeita com os preços que recebem. Dentre as razões que foram apontadas como responsáveis por este descontentamento estão os preços muito baixos, a elevada concorrência em função do grande número de produtores e os elevados preços dos insumos agrícolas.

Como sugestão para melhorar os preços dos hortifrutigranjeiros, os produtores insatisfeitos apontaram, por ordem de importância, a necessidade de um planejamento maior dos produtores possibilidade para evitar supersafras, a criação de mais pontos de venda, a possibilidade de vender direto ao consumidor sem a intermediação dos atravessadores, a formação de uma associação de produtores que estabeleceria o preço do dia, a redução dos preços dos insumos, a industrialização dos produtos e a busca de qualidade dos hortifrutigranjeiros.

Por outro lado, os produtores que responderam estar satisfeitos com os preços que recebem, $41,1 \%$ apontaram como principais motivos a manutenção de uma clientela fixa, o Plano Real, a produção na entressafra, o melhor rendimento dos hortifrutigranjeiros relativamente às culturas anuais, o baixo custo de produção que possibilita a obtenção de lucro e os preços satisfatórios quando o produto tem qualidade.

Na busca por melhor qualidade dos produtos, os entrevistados procuram seguir corretamente as orientaçōes técnicas, utilizando adubação química e orgânica, defensivos, verificando o prazo de carência dos agrotóxicos, fazendo calcareamento do solo, usando irrigação, sementes melhoradas, estufas, espaçamento adequado, além de classificar os produtos, não plantar grandes áreas, buscar novas variedades, dispensar cuidados na colheita e no transporte e fazer treinamento de mão-de-obra.

Com relação à sobra na comercialização, os produtores apontaram as verduras com um percentual de $13,8 \%$ enquanto as frutas e os legumes ficaram com $11,2 \%$ e $9,5 \%$, respectivamente.

Para melhorar o processo de comercialização, os produtores solicitaram ampliação do número de locais de venda direta ao consumidor, melhor adaptação 
das embalagens aos produtos, uma política de controle de qualidade, ampliação e melhoria da cobertura do Mercadão, criação de associação dos produtores para que possam reivindicar melhores preços, eliminação dos atravessadores e venda direta à agroindústria.

\section{2 - Caracterizaçāo dos atacadistas}

Dos 60 atacadistas entrevistados, apens $18,3 \%$ disseram fazer parte de associaçōes e sindicatos.

No que se refere à procedência dos hortifrutigranjeiros comercializados em Londrina, a concentração se dá, basicamente, no próprio municipio, com destaque para alface, cenoura, couve-flor, feijãovagem, mandioca, repolho, abacate, maracujá e poncã, e em São Paulo, onde a batata doce, cebola, banana caturra, laranja, mamão, melancia e morango se sobressaem.

Em seguida aparecem os municípios da região que complementam a produção do município com abobrinha, beterraba, chuchu, pepino, pimentão, uva e ovos. O município, os municípios da região e São Paulo aparecem como importantes fornecedores de pimentão e tomate. Na sequência, o Estado do Paraná aparece como o grande fornecedor complementar de cebola, depois de São Paulo e Santa Catarina. No que se refere aos outros Estados, Minas Gerais se destaca com o abacaxi, Santa Catarina com a cebola, maçã e melancia e Goiás com a melancia. Em relação a países, a Argentina aparece como fornecedor complementar de cebola.

Nota-se que a maior dependência de Londrina em relaçāo ao fornecimento de outros Estados se concentra no grupo frutas, especialmente abacaxi, mamão e melancia.

No que se refere ao processo de compras e transporte dos produtos comercializados pelos atacadistas, $65 \%$ afirmaram negociar diretamente com produtorese intermediários (atacadistas ou importadoras) e 56,7\% disseram usar veículo próprio.

Quanto às exigênias feitas aos produtores/fornecedores, $41,7 \%$ dos atacadistas mencionaram prazo para pagamento e classificação do produto, enquanto $28,3 \%$ se referiram apenas à classificação do produto e $11,7 \%$ somente a prazo.

O preço de compra dos produtos é determinado pela oferta e procura para $60 \%$ dos entrevistados, enquanto que para $20,0 \%$ o preço é determinado pelos produtores ou intermediários atacadistas. Na compra dos produtos, o pagamento é feito apenas a prazo para $75 \%$ dos atacadistas e a periodicidade mais freqüente é de até 15 dias.

No que se refere à qualidade dos produtos que compram, $100 \%$ dos atacadistas revelaram preocupação, sendo que $70,0 \%$ argumentaram que o principal motivo são os compradores exigentes, a facilidade na comercialização e o melhor preço dos produtos de boa qualidade.

Relativamente à classificação/padronização dos produtos vendidos pelos atacadistas, $55 \%$ dos entrevistados afirmam fazer algum tipo, ao passo que $45 \%$ disseram não fazer classificação por comprar os produtos já classificados. No que se refere ao tipo de classi- ficação feita nos produtos, $84,8 \%$ dos atacadistas afirmaram classificar por tamanho ou qualidade (tipo). Dentre as razões alegadas pelos atacadistas que fazem alguma classificação, 39,4\% apontaram a exigência dos compradores/consumidores e $24,2 \%$ disseram que a faz por que os produtos săo altamente pereciveis.

Quanto à sobra no processo de comercialização, $91,7 \%$ dos atacadistas afirmaram tê-la, sendo a sobra média de verduras de $16 \%$, de legumes de $12,2 \%$ e de frutas de $11,9 \%$.

Questionados sobre para onde são vendidos os produtos, $90 \%$ dos atacadistas afirmaram vender, em média, $27,5 \%$ dos hortifrutigranjeiros em supermercados, $88,3 \%$ disseram vender, em média $24,7 \%$ nos sacolōes, $78,3 \%$ vendem, em média, $22,3 \%$ nas feiraslivres e $55 \%$ vendem, em média, $21,3 \%$ para outros atacadistas.

A forma de determinação do preço de venda dos produtos mencionada por $61,7 \%$ dos atacadistas foi 0 estabelecimento de uma margem sobre o preço de compra, enquanto $30 \%$ disseram estabelecer uma margem de lucro.

Na venda dos produtos, $66,7 \%$ dos atacadistas afirmaram que o recebimento é a prazo, enquanto $33,3 \%$ disseram receber a vista e a prazo, sendo que a periodicidade é de até 15 dias para $68,3 \%$ dos entrevistados.

Indagados se estão satisfeitos com os preços que recebem pelos produtos que vendem, $56,7 \%$ disseram que sim. Destes, $82,4 \%$ justificaram sua satisfação dizendo que dá para manter a atividade. Por outro lado, dos insatisfeitos, que totalizam $43,3 \%$, metade argumentou que a atividade, às vezes, não repõe o capital investido e $30,8 \%$ alegaram que a margem de lucro é mínima. Como sugestão para melhorar os preços, $26,9 \%$ dos insatisteitos sugeriram a redução dos tributos e $23,1 \%$ a redução dos encargos sociais.

\section{3 - Caracterização dos varejistas}

Dos varejistas entrevistados, $72,6 \%$ não são filiados ou vinculados a associação de classe ou entidade representativa. No que tange às categorias, observou-se que a mais organizada é a supermercado, onde $68,2 \%$ são filiados a alguma associação. Nesta, a APRAS (Associação Paranaense de Supermercados) é a principal entidade de classe. Destacam-se, ainda, a ALES (Associação Londrinense de Empresários Supermercadistas) e o Sindiato dos Varejistas de Londrina.

No tocante às compras dos hortifrutigranjeiros pelos varejistas, constatou-se que a maioria adquire os produtos, com maior freqüência, no Mercadão, na CEASA-Lda e diretamente do produtor, respectivamente. Com relação às categorias, os supermercados têm como principal local de compra a CEASA-Lda, seguida do Mercadão. Por outro lado, os feirantes e os sacolões compram mais no Mercadäo, enquanto os varejistas do Mercado Municipal, praticamente, dividem suas compras entre a CEASA-Lda e o Mercadão.

A compra direta do produtor, isto é, sem intermediários, é relevante para vários produtos, destacando- 
se a poncã, o alface, os ovos, o morango, a mandioca e a uva. Cerca de $40 \%$ dos varejistas entrevistados compram mais de $75 \%$ destes produtos diretamente do produtor.

Dentre os varejistas entrevistados, $67,1 \%$ não realizam compra fora do município de Londrina. Para estes, o contato para a realização dos negócios é feito diretamente em $64,4 \%$ dos casos, sendo o transporte próprio para $56,2 \%$ dos varejistas. Por outro lado, dos agentes que adquirem produtos fora de Londrina, cerca de $54,2 \%$ utilizam-se de contato direto e $33,3 \%$ de contato telefônico. O transporte dos produtos fica por conta dos fornecedores em $79,2 \%$ dos casos.

No processo de formação do preço de compra, $53,4 \%$ dos entrevistados informaram que este é determinado pelo mercado, isto é, pela oferta e procura dos produtos. Para 31,5\% dos varejistas, os preços dos produtos são determinados pelos fornecedores e para $10,9 \%$ pelos fornecedores conjugado com negociação entre as partes.

No que se refere às exigências feitas aos fornecedores pelos varejistas, constatou-se que a principal delas é a classificação dos produtos, seguida pelo preço e assiduidade na entrega.

Na compra dos produtos, $41,9 \%$ dos entrevistados fazem os pagamentos a vista e a prazo. O pagamento a vista é realizado por $29,7 \%$ dos varejistas, enquanto $25,7 \%$ fazem-no a prazo. Em geral, $84 \%$ dos varejistas tem até 15 dias para efetuar seus pagamentos.

Todos os agentes varejistas entrevistados se preocupam com a qualidade dos produtos que compram. A principal razão alegada é a exigência dos consumidores.

Os dados mostram que $58,9 \%$ dos varejistas entrevistados não fazem classificação ou padronização dos produtos que compram, alegando que os produtos chegam até eles classificados.

Todos os agentes varejistas declararam ocorrer alguma sobra dos produtos que comercializam. Em média, as sobras totais, que refletem parte dos produtos não comercializados, montam $18,8 \%$ para verduras, $17,6 \%$ para legumes, $14,5 \%$ para frutas e $6,1 \%$ para ovos. É importante ressaltar que, destas sobras, parte significativa é doada, príncipalmente, a entidades filantrópicas.

Dos agentes varejistas entrevistados, $90,3 \%$ classificam os consumidores como exigentes e muito exigentes, o que vem de encontro com a preocupação dos varejistas com a qualidade dos produtos que comercializam.

A determinação dos preços de venda pelos varejistas e feita com o estabelecimento de uma margem de comercialização sobre o preço de compra dos produtos.

As vendas dos produtos hortifrutigranjeiros pelos varejistas se dão a vista em $50,7 \%$ dos casos e a vista e a prazo em $49,3 \%$, não sendo observadas vendas somente a prazo.

A melhoria no processo de comercialização para os varejistas de hortifrutigranjeiros londrinenses, em ordem de importância, ocorrerá quando forem aumentadas as compras diretas e aprimoradas as embalagens dos produtos, melhoradas a infra-estrutura do Mercadão, a educação dos consumidores na escolha dos produtos, a exposição e propaganda dos produtos, as condições de produção para os produtores e a qualidade e classificação dos produtos.

\section{4 - Caracterização dos consumidores}

Dos consumidores londrinenses entrevistados, $81,1 \%$ compram hortifrutigranjeiros até 2 vezes por semana, sendo que $52 \%$ o fazem apenas 1 vez por semana. Estas compras são realizadas em supermercados por $60,8 \%$ dos consumidores, com $29,4 \%$ comprando $100 \%$ e $13,7 \%$ comprando mais de $50 \%$ em supermercados. Em segundo lugar, aparecem os sacolões, com $39,9 \%$ dos consumidores, sendo que $13,8 \%$ compram $100 \%$ e $10,3 \%$ mais de $50 \%$. As feiras-livres se colocam em terceiro lugar com $22 \%, 3,5 \%$ e $5,9 \%$, respectivamente. A classe de renda de mais de $10 \mathrm{SM}$ foi a que mais apresentou consumidores comprando $100 \%$ de hortifrutigranjeiros em supermercados, $33,1 \%$ dos entrevistados, enquanto a classe de 2 a 4 SM apresentou a maior percentagem de consumidores comprando $100 \%$ em sacolōes, $20,3 \%$.

A escolha dos locais de compra é feita pela proximidade de casa por $21,1 \%$ dos consumidores entrevistados, pelo preço e qualidade por $17,4 \%$ pelo preço por $16,4 \%$ e pela qualidade por $13,3 \%$, considerados separadamente. Por outro lado, $47,6 \%$ dos consumidores mencionaram o preço como critério de escolha dos locais de compra, $43,5 \%$ a qualidade e $41,4 \%$ a proximidade de casa. $\dot{E}$ interessante notar que o preço é o critério mais importante para a escolha dos locais de compra para as classes de menor renda, enquanto a qualidade passa a ser mais considerada na medida do aumento da renda. A proximidade de casa apresenta importância semelhante para todas as classes.

Os produtos são escolhidos pela conjugação do preço com a qualidade por $70,7 \%$ dos consumidores entrevistados, pela qualidade por $21,7 \%$ e pelo preço por $7,1 \%$.

As Feiras de Produtos de Época, não são freqüentadas por $57,1 \%$ dos consumidores entrevistados. Por outro lado, $42,9 \%$ dos consumidores já compraram algum tipo de produto nestas feiras, sendo a da uva freqüentada por $42,7 \%$ dos entrevistados, seguida pela da uva e do morango, $30,9 \%$ e pela do morango, $17,5 \%$. Quanto às opiniōes dos frequentadores das Feiras de Época, 43,4\% dos entrevistados afirmaram que o preço e a qualidade são bons, $16,9 \%$ apontaram a boa qualidade e $15,5 \%$ o bom preço. Conjugando bom preço e qualidade aparecem $75,8 \%$ dos consumidores. Cabe ressaltar que as classes de renda mais alta compram mais neste tipo de feira do que as de menor renda.

Para facilitar as compras de hortifrutigranjeiros, $13,9 \%$ dos consumidores sugeriram reduzir preços e $11,2 \%$ melhorar a qualidade dos produtos. Os consumidores satisfeitos com o processo de compras somam $31 \%$. 


\section{4 - Consideraçōes Finais}

As informaçōes levantadas no período de julho/ 94 a junho/95 a nível de produtores, atacadistas e varejistas de hortifrutigranjeiros em Londrina permitiram constatar características importantes destes agentes.

A nível de produtores, verificou-se que a maioria é proprietário com área de até 10 ha, cultiva $85,7 \%$ dos produtos mais comercializados e, portanto, mais consumidos no município, os quais são vendidos em grande parte no Mercadão, sendo o preço de venda determinado pelo mercado. Isto revela a dependência total do mercado londrinense apenas com relação a batata inglesa, abacaxi, mamão e melancia.

A preocupação com a qualidade e a classificação dos produtos é uma constante entre os produtores. No entanto, apenas metade deles recebe orientação técnica. Por outro lado, $98 \%$ dos produtores praticam algum tipo de classificação dos seus produtos, que pode ser por tamanho, cor, qualidade e grau de maturação.

No que se refere aos atacadistas, constatou-se que a categoria se concentra no Mercadão, sendo que a maioria deles vende seus produtos para supermercados, sacolões e feiras-livres a preços que incorporam uma margem sobre o preço de compra.

Quanto aos varejistas, a maioria adquire os produtos, com maior freqüência, no Mercadão, na CEASALda e diretamente do produtor, respectivamente. A compra direta do produtor, isto é, sem intermediários, é relevante para vários produtos, destacando-se a poncã, o alface, os ovos, o morango, a mandioca e a uva. Cerca de $40 \%$ dos varejistas entrevistados compram mais de $75 \%$ destes produtos diretamente do produtor.
Na determinação dos preços de venda, a exemplo do que ocorre com os atacadistas, os varejistas também estabelecem uma margem sobre o preço de compra dos produtos.

Desse modo, a cadeia de comercialização de hortifrutigranjeiros de Londrina se apresenta na forma tradicional, onde o Mercadão se constitui no principal elo de ligação entre produtores e varejista, uma vez que é naquele local que ocorre grande parte das transações destes produtos no mercado londrinense.

A preocupação com a qualidade dos hortifrutigranjeiros também está presente entre os atacadista e varejista, o que mostra que a melhoria na qualidade terá que vir dos agentes precedentes da cadeia de comercialização, cabendo aos produtores maior parcela de contribuição neste processo. Isto, certamente, ajudará a reduzir os altos níveis de perdas constatados durante a comercialização.

Por fim, dos consumidores londrinenses, $81,1 \%$ compram hortifrutigranjeiros até duas vezes por semana, sendo que estas compras são realiadas em supermercados por $60,8 \%$ dos consumidores.

Os critérios para a escolha dos locais de compra apontados pelos consumidores são os preços, a qualidade e a proximidade de casa, respectivamente. Vale ressaltar que o preço é o critério mais importante para a escolha dos locais de compra para as classes de menor renda, enquanto a qualidade passa a ser mais considerada na medida do aumento da renda.

Por fim, as Feiras de Produtos de época são freqüentadas pelos consumidores das classes de renda mais alta.

RODRIGUES, R.L.; MORETTO, A.C.; FERREIRA, C.R. The characteristics of horticultural products market in Londrina. Semina: Londrina, Ci. Sociais/Humanas, v. 17, n. 3, p. 345-349, Sep. 1996.

ABSTRACT: The objective of this text is to publish the first information about the caracteristics of agents that compose de horticultural products market in Londrina. Twenty eight products, considered the most important and the most comercialized in the city, were analysed. Data were collected from fieldwork covering local producers, wholesalers, retailers and consumers. The study showed the passivitiy of producers in the information of prices, the small dependence of Londrina relating to external markets, the importance of the supermarket as a connection point between producers and retailers and the predominance of supermarkets in horticultural trading activity.

KEY-WORDS: horticultural products - trading activity - market

\section{BIBLIOGRAFIA}

ASSUMPÇÃO, A.G. de et al. Estudo de formação de preços de hortifrutigranjeiros e cereais em Maringá. Revista de Economia e Sociologia Rural, Brasilia, v. 28, n. 1, p. 89-104, jan./fev./mar., 1990

BRAMBILA, P.H.M. O mercado atacadista de hortícolas de Londrina: uma abordagem histórico-estrutural. Londrina, 1993, 70 p. Monografia (Graduação em Ciências Econômicas) Universidade Estadual de Londrina.

EMATER. Empresa Paranaense de Assistência Técnica e Extensão Rural. Plantio de hortaliças no município de Londrina. 1991, 5 p. Estatísticas sobre o plantio de hortaliças no cinturăo verde de Londrina
HOFFMANN, R. et al. Administração da empresa agricola. $1^{\text {a }}$ ed. São Paulo: Pioneira, 1984. $380 \mathrm{p}$.

MARTINS, Nilza Lustosa; Lopes, Eudes Torro. A feira livre. Uma contribuição ao estudo de suas características e os fluxos de sua comercialização: o exemplo de Londrina. Londrina, 1977, 201 p. Monografia (Especialização em Organização do Espaço Base) - Centro de Estudos Superiores de Londrina - CESULON).

REZENDE, A.M.; AAD NETO, A. Comercialização agrícola. 1a ed. Viçosa: Imprensa da Universidade Federal de Viçosa, 1981. $53 \mathrm{p}$. 